\title{
New Generation of Electrochemical Sensor for Sub- Nanomolar Zn (II) Ion Detection Based on Nano- Sized Ion Imprinted Polymer and Functionalized Multi-Walled Carbon Nanaotube Composite Modified Glassy Carbon Electrode
}

Vali Alizadeh ( $\nabla$ valializadeh.chem@gmail.com )

University of Garmsar https://orcid.org/0000-0001-7246-7839

Nasrin Behnia

2Islamic Azad University Central Tehran Branch

Mehdi Asgari

United Arab Emirates

Research Article

Keywords: Ion Imprinted Polymer, Multi-walled Carbon Nanotube, Square wave Anodic Stripping Voltammetry, Glassy carbon electrode

Posted Date: July 14th, 2021

DOI: https://doi.org/10.21203/rs.3.rs-686951/v1

License: (9) This work is licensed under a Creative Commons Attribution 4.0 International License. Read Full License 


\section{Abstract}

A new selective and sensitive electrochemical sensor was prepared by film coating of Zinc (II) ion imprinted polymer (IIP) nanoparticle and functionalized multi-walled carbon nanotube (MWCN) composite on glassy carbon electrode (GCE). The prepared electrochemical sensor was applied for the sensitive determination of Zinc (II) ion by square wave anodic stripping voltammetry (SWASV) method. The GCE/IIP-MWCNT modified electrode showed improved electrochemical behavior as compared to bare $\mathrm{GC}$ electrode. An optimum procedure was used for the fixation of $\mathrm{Zn}(\mathrm{II})-8$-hydroxyquinoline to styreneethylene dimethacrylate copolymer and the resultant IIP nanoparticles characterized by Fourier Transform Infrared (FTIR), thermal gravimetric analysis (TGA), and scanning electron microscopy (SEM). The effects of different experimental variables such as $\mathrm{pH}$, deposition time, and deposition potential were optimized for electrochemical determinations. The resultant IIP showed a selective sorbent for Zinc (II) ion. Functionalized MWCNT was applied in construction of as prepared modified electrode, exhibits large surface area, enhanced electron transfer kinetics, and improved Zn (II) ion diffusion. Under the optimal conditions, the resulting calibration curve exhibited a linear response within a concentration range of $5 \times 10^{-12}$ to $15 \times 10^{-8} \mathrm{~mol} / \mathrm{L}^{-1}$ with excellent detection limit $5 \times 10^{-12} \mathrm{~mol} / \mathrm{L}^{-1}$. Finally, the method was successfully applied for the determination of zinc (II) ion in the real water samples, and the obtained results were verified by inductively coupled plasma (ICP).

\section{Introduction}

Analysis of Zinc (II) ion is very important not only from the biochemical point of view but also from the environmental one. Zinc (II) ion plays a central role in a variety of fundamental biological processes such as in cell reproducing and nucleic acid metabolism, and its low physiological concentration is connected with some pathological processes like retarded growth and immunity dysfunctions [1]. On the other hand, contamination of waters by Zinc (II), as a heavy metal ion, causes a worldwide environmental problem [2, 3]. Zinc (II) is often found in effluents discharged from industries [2-4]. The maximum acceptable Zinc (II) concentration in drinking water in $5 \mathrm{mg} / \mathrm{L}$ and toxicity for humans is $100-500 \mathrm{mg} / \mathrm{d}$ [5]. Therefore, determination and removing excess of Zinc (II) from wastewater is of great important.

Several techniques have been developed for the measurement of Zinc (II) such as spectrophotometric [6], chromatographic [7] and electrochemical [8]. Among these techniques, electrochemical techniques are an efficient one due to their fast response, excellent selectivity, high sensitivity, simplicity and low cost. Anodic stripping voltammetry (ASV) is a commonly used electrochemical technique for electrochemical trace metal ion analysis. This technique comprises preconcentration and stripping steps, so in the first step, metal ions at a low concentration accumulated on the electrode surface which improves sensitivity and detection limit [9-11]. In trace analysis of metal ions, ASV is the most popular with square wave voltammetry (SWV) technique [12-14]. In these studies, many different electrodes are used, among them GCE offer many useful properties of low background current, low cost, wide potential windows and easy surface modification [15-16]. Whilst, bare GCE has useful properties, reports have shown shortcomings 
associated with use of bare GCE, such as its small surface area and sensitivity due to slow electron transfer kinetics on it [17-18].

However, the electrochemical performances of working electrodes have been improved by modification especially with multi-walled carbon nanotube (MWCNT) as a carbon-based nanomaterial owing to its remarkable active surface area, chemical inertness, high strength, and low charge-transfer resistance in both aqueous and non-aqueous solutions [19-30]. Here we used functionalized MWCNT based ion imprinted polymer (IIP) as a modifier for GCE modification.

Today, IIP materials, as a class of smart polymers, containing a large number of metal ion recognition cavities were designed for the selective recognition and separation of target metal ions, due to its low cost, outstanding selectivity, and high electrochemical stability [30-32]. These polymers are prepared by using metal ions with a functional monomer used as a complexing agent in presence of cross-linking agent and initiator. Then, strong acid is used to leach out the metal ion from the imprinted polymer to form selective template cavities [33-37]. During the IIPs synthesis, the morphology of the prepared particles can be controlled by varying the experimental conditions such as solvent volume, temperature and stirring speed of polymerization solution, specially the cross-linker/monomer feed ratio as a decisive factor in selective adsorption of target metal ions [38, 39].

In this study, a novel electrochemical sensor for Zn (II) ion sensing was constructed by ion imprinting approach in the cross-linker/monomer feed ratio of 8. The synthesized IIP nanoparticles and its behavior after removing zinc (II) ions were described. The IIP and functionalized MWCNT nanocomposite was utilized for modification of GCE. Functionalized MWCNT was used to increase the surface area, enhance electron transfer kinetics, and facile Zinc (II) diffusion, resulting enhancement in modified electrode sensitivity. The electrochemical behaviors of Zinc (II) were studied in detail on modified electrode. After optimization of parameters, the calibration curve was prepared and its linear regression and limit of detection (LOD) were determined. The prepared modified electrode was successfully applied to determine Zinc (II) ion concentration in the real sample.

\section{Experimental}

\subsection{Instrumentation and Measurement Conditions}

Electrochemical measurements were carried out using a Metrohm Autolab potentiostate/galvanostate (model $302 \mathrm{~N}$ ) under pure Argon atmosphere. A conventional three-electrode electrochemical cell was used in which modified GCE as a working electrode, saturated $\mathrm{Ag} / \mathrm{AgCl}$ as a reference electrode, and platinum electrode served as counter electrode for electrochemical measurements. A BRUCKER vector 22 FT-IR spectrophotometer was applied to characterize imprinted and non-imprinted polymers using the $\mathrm{KBr}$ pressed disk method in the scan wave number range of $400-4000 \mathrm{~cm}^{-1}$. The morphology of the IIPMWCNT film was characterized by Scanning electron microscope (SEM, Philips model XL 30) 
Thermogravimetric analyzer (TGA, Rheometric scientific, Model STA1500) was used to evaluate a thermal stability of prepared IIPs.

\subsection{Chemical and Solutions}

Zinc Chloride tetrahydrate $\left(\mathrm{ZnCl}_{2} \cdot 4 \mathrm{H}_{2} \mathrm{O}\right)$, 8-Hydroxyquinoline (oxine), MWCNTs, 2,2'-azobisisobutyronitrile (AIBN), Ethylene glycol dimethaacrylate (EGDMA), styrene, 2-methoxyethanol, Nafion solution (5wt\%), and Hydrochloric acid were obtained from Fluka. All the above chemicals were of analytical grade and used as received without any further purification. Double distilled deionized water was used for preparation of solutions.

\subsection{Preparation of $\mathrm{Zn}$ (II) ion imprinted and non-imprinted polymeric nanoparticles}

A thermal polymerization technique was used to prepare the $\mathrm{Zn}$ (II) imprinted nanobeads. For this purpose, $1 \mathrm{mmol}$ of $\mathrm{Zn}^{2+}$, as imprint metal ion and $2 \mathrm{mmol}$ of oxine, as ligand were added into $10 \mathrm{~mL}$ of 2-methoxyethanol, as porogen solvent and continuously stirred for $15 \mathrm{~min}$ to proceed complexation reaction. Then, $32 \mathrm{mmol}$ EGDMA, as cross linker agent, $4 \mathrm{mmol}$ styrene, as monomer, and $0.3 \mathrm{mmol}$ AIBN as initiator, were added to the above mixture and to avoid polymerization retardation, nitrogen gas purged for $10 \mathrm{~min}$ to remove molecular oxygen from it, then sealed. The reaction vial was set-up in oil bath at $60^{\circ} \mathrm{C}$ for $24 \mathrm{~h}$ under magnetic stirring to complete the thermal polymerization. After polymerization, the resulting light yellow products were washed several times with deionized water, dried and then grinded. The obtained IIP nanoparticles, were used to leaching process under stirring condition with $6 \mathrm{~mol} \mathrm{~L}^{-1} \mathrm{HCl}$ for $12 \mathrm{~h}$ for removing $\mathrm{Zn}$ (II) ion and produce polymer cavities. Then, the precipitated particles were washed using high purity deionized water until a neutral $\mathrm{pH}$ value is set. Finally, the obtained white IIPs powders were dried at $60^{\circ} \mathrm{C}$ under vacuum condition. The non-imprinted polymer (NIP) was prepared in the similar manner to that of the IIP, but in the absence of Zn (II) ion. The prepared IIP and NIP were used to fabrication of modified GCE.

\subsection{Preparation of IIP-MWCNT/GCE Modified Electrode}

Prior to use, MWCNTs were functionalized by oxidative treatments with a mixture of nitric acid and sulfuric acid solution to enhance adsorption of Zinc (II) ions with imposed oxygen-containing functional groups on MWCNTs at the preconcentration steps. Oxidation methods are an effective method to functionalize the surface of MWCNTs, but a bad control of the oxidation conditions causes serious structural damage in MWCNTs. To avoid MWCNT destruction, promote and increase in the $-\mathrm{COOH}$ groups onto MWCNTs surface, we followed the optimal condition to perform functionalization of MWCNTs as reported by L. Thi et al. [40]. Briefly, MWCNT was refluxed in a 1:3 mixture of 4.0 M $\mathrm{HNO}_{3} / 10.0 \mathrm{M} \mathrm{H}_{2} \mathrm{SO}_{4}$ at the treatment time of 18 hours then washed with double distilled deionized water several times for acid neutralization, finally the functionalized MWCNTs were dried. To prepare IIPMWCNT/GCE modified electrode, the bare GCE was polished with $0.05 \mu m \mathrm{Al}_{2} \mathrm{O}_{3}$ slurry on a polishing micro-cloth and then washed by acetone and deionized water to remove the residues. Next, a 
homogenized IIP-MWCNT mixture was prepared by dispersing functionalized MWCNTs and IIP nanoparticles in deionized water and $0.5 \%$ Nafion, using a low power sonicator to form a stable dispersion for $15 \mathrm{~min}$. A $10 \mu \mathrm{L}$ aliquot of prepared dispersion was dropped on the GCE surface and left to dry in air before being used.

\subsection{Electrochemical Measurements}

All measurements were performed in a $50 \mathrm{~mL}$ solution containing $\mathrm{HCl}(\mathrm{pH} 3.7)$ as a supporting electrolyte. The solution was transferred into a dry electrochemical cell and was purged by high purity argon gas for 10 min before performance of SWASV measurements. The pre-concentration step was carried out at stirring speed of $650 \mathrm{rpm}$. The voltammogrm was recorded between -0.4 and $+0.4 \mathrm{~V}$ by applying square-wave modulation with $0.0015 \mathrm{~V}$ step amplitude, $0.02 \mathrm{~V}$ pulse amplitude, and frequency of $8 \mathrm{~Hz}$.. All experiments were performed at room temperature.

\section{Results And Discussion}

\subsection{Characterization of Zn (II) Ion Imprinted Polymer Particles}

The resulting IIP nanoparticles obtained from thermal copolymerization were characterized by FT-IR spectroscopy, scanning electron microscopy (SEM) and thermal gravimetric analysis (TGA).

In addition, the morphological structure of IIP-MWCNT film on modified GCE was evaluated by SEM. Figure 2 shows the entangled network structure of functionalized MWCNTs entrapped into the globular IIPs nanoparticles and proves the more rigid composite formation accompany with accessible nanopores. It is clear that, the irregularity in nanopolymer size is observed but the most portions of the IIP particles are below $50 \mathrm{~nm}$. However, it is well recognised that, in this type of polymerization, the morphology of the individual particles can be improved by varying the experimental conditions [38]. The prepared nanobead provides more available surface area for Zn (II) ions diffusion into the polymer.

For further investigation, the resulting IIP nanoparticles were characterized by thermogravimetric analysis (TGA). We have studied the thermal decomposition of this polymer in inert gas. The TGA curve shows the high thermal stability of this synthesized polymer (up to $300^{\circ} \mathrm{C}$ ) (Fig. 3).

\subsection{Cyclic Voltammetry and Electrochemical Impedance Spectroscopy of IIP-MWCNT Film on Modified GCE}

$\mathrm{CV}$ and EIS techniques were employed to characterize the modified electrode. Figure 4A shows the CVs of $5 \mathrm{mM} \mathrm{Fe}(\mathrm{CN})_{6}{ }^{3-/ 4-}$ measured at bare GCE and modified IIP-MWCNTs/GCE electrodes in a $0.1 \mathrm{mM}$ phosphate buffer solution ( $\mathrm{pH} 7.0)$, recorded at scan rate of $50 \mathrm{mV} / \mathrm{s}$. 
As seen, the peak current at IIP-MWCNT/GCE is increased over that at the bare GC electrode. A pair of well-defined quasireversible redox peaks stands for the reduction and oxidation of $\mathrm{Fe}(\mathrm{CN})_{6}{ }^{3-/ 4-}$ redox couple. The significant difference between the two CVs indicates the successful dispersion of MWCNTs into the IIP bulk. This results demonstrate that the successful dispersion of MWCNTs into the IIP opens an efficient path for ET between $\mathrm{Fe}(\mathrm{CN})_{6}{ }^{3-/ 4-}$ redox couple and GCE by enhancing charge transfer kinetics [41].

EIS technique was applied in order to investigate the interfacial properties of the modified electrode. This technique is a powerful one for probing the conductivity properties of the coated films. Nyquist diagrams for $5.0 \mathrm{mM} \mathrm{Fe}(\mathrm{CN})_{6}{ }^{3-/ 4-}$ redox probe (1:1 molar ratio) in $0.1 \mathrm{M}$ phosphate buffer solution $(\mathrm{pH} 7.0)$ for bare and modified electrode are showed in Fig. 4B. As it is seen, the resulting Nyquist plots shows a semicircle domain at higher frequencies reflects the electron transfer kinetics of the surface with a diameter equal to the charge transfer resistance $\left(R_{\mathrm{ct}}\right)$; while the linear part at lower frequencies corresponds to the diffusion process. The $\mathrm{R}_{\mathrm{ct}}$ value, derived from the semicircle domain of the EIS plot, was found to be $2 \mathrm{k} \Omega$ for GCE (Fig. 4B). However, the dramatically decrease of $\mathrm{R}_{\mathrm{ct}}$ after modification of GCE with IIP-MWCNTs, indicated that electron transfer was much more efficient onto the modified electrode. The EIS result was consistent with the cyclic voltammetry and both techniques showed successful modification of GCE.

\subsection{Influence of the pH Value on Peak Current}

As the sorption and desorption of metal ions into IIPs be considerably affected by solution $\mathrm{pH}$, therefore, it is the first and most important parameter that should be optimized to find the most suitable condition for Zn (II) ion detection. Voltammograms were obtained using modified electrode for a zinc (II) solution of $1.0 \times 10^{-6} \mathrm{~mol} \mathrm{~L}^{-1}$ in $\mathrm{HCl}$ according to the variation of the $\mathrm{pH}$ values in the range of 1.0 to 5.0. Several electrolytes were tested as a supporting electrolyte (Sodium Acetate, Sodium Nitrate, Sodium Citrate and $\mathrm{HCl}$ ), but $\mathrm{HCl}$ gave the best response. The $\mathrm{pH}$ dependence of the anodic peak intensities is shown in Fig. 5. The results revealed a gradually increased in the intensity of zinc (II) signal by increasing pH of solution with the best peak height at $\mathrm{pH}$ 3.7. The low analytical signal was observed at $\mathrm{pH}$ values lower than 3.7, probably due to competition between $\mathrm{Zn}$ (II) and $\mathrm{H}^{+}$ion to capture polymer binding sites. The solutions with higher pHs were not investigated because of Zinc (II) ion hydrolysis and its precipitation possibility, which decreases $\mathrm{Zn}$ (II) concentration in sample solution. Based on these results, $\mathrm{HCl}$ solution of $\mathrm{pH} 3.7$ was chosen to be used in subsequent studies.

\subsection{Effect of Deposition Time and Potential}

Preconcentration time is the main parameter in SWASV response of Zn (II) ions and resultant has an outstanding effect on sensitivity of the modified electrode. The preconcentration time was checked in the range of 100 to $1100 \mathrm{~s}$ to find the maximum electrochemical signal by applying the constant potential, $-500 \mathrm{mV}$ in $\mathrm{HCl}$ solution (pH 3.7). Figure 6A shows an improvement in response of Zinc (II) ion with 
increasing preconcentraion time suggesting that a high amount of Zinc (II) ions were concentrated at the modified electrode surface. The maximum electrochemical signal occurs at $800 \mathrm{~s}$ of contact time therefore it was chosen to be employed in subsequent studies although a longer accumulation time is recommended for zinc determinations at concentrations close to detection limit.

In order to obtain the best value of applied potential for zinc (II) ion detection, the effect of preconcentration potential was investigated at -100 to $-900 \mathrm{mV}$ in Zinc(II) concentration of $1 \times 10^{-6} \mathrm{M}$ and deposition time of $800 \mathrm{~s}$ (pH 3.7). Figure 6B shows the correlation of the anodic peak current intensity with the value of the applied potential. The results showed that the current intensity considerably increases first and reaches to the maximum at $-400 \mathrm{mV}$, and then decreases. At more negative potential values the current decreases greatly, probably because of hydrogen evolution at the more negative potential. Thus, the optimum preconcentration potential should be $-400 \mathrm{mV}$ for sensitive subsequent experiments.

\subsection{Calibration Curve}

The analytical performances of the modified electrode for Zn (II) ion determination were evaluated under the best set of operational conditions. As shown in Fig. 7, the anodic response was linear with the concentration of Zinc (II) ranging from 0.001 to $1.5 \mathrm{nM}$, with a correlation coefficient of 0.9987 . The lowest detectable concentration (three times the blank signal/slope) of $\mathrm{Zn}$ (II) at accumulation time of $1000 \mathrm{~s}$ was evaluated to be $5 \times 10^{-12} \mathrm{M}$, which indicates the sensitivity of the IIP-MWCNT/GCE. The relative standard deviation for ten replicate measurements of $2.0 \mathrm{nM}$ of zinc (II) ion was found to be $3.3 \%$. The reproducibility was evaluated by fabrication of three modified electrode under the same conditions. The RSD $4.1 \%$ resulted, suggesting that the IIP-MWCNT/GCE exhibits accurate reproducibility towards the determination of zinc (II) ion.

In order to examine the reusability, the IIP-MWCNT/GCE was subjected to 16 times of detection/elution cycles under optimal conditions. After each use, $5.0 \mathrm{~mL}$ of $6 \mathrm{M} \mathrm{HCl}$ solution was used for elution of the adsorbed Zn (II) ions and regeneration of the IIP. The experiments showed that, the modified electrode lose its adsorption capacity by about $4.9 \%$ after 16 repeated uses. Thus, the IIP-MWCNT/GCE could repeatedly be used with high efficiency in selective detection of $\mathrm{Zn}$ (II) ions from aqueous solutions.

The electrochemical signal of Zinc (II) ion was investigated in the presence of some possible interference from common metal ion such as: $\mathrm{Ni}^{2+}, \mathrm{Co}^{2+}, \mathrm{Cd}^{2+}$ and $\mathrm{Cu}^{2+}$. Voltammetric detection was performed in the presence of excess amount of these interferent ions. The change in Zinc (II) response was less than $4.5 \%$ in the presence of the above interferent ions. This means that there was no interference on the $\mathrm{Zn}$ (II) determination.

To evaluate the potential practical applications, the IIP-MWCNT/GCE was also used for determination of trace levels of $\mathrm{Zn}$ (II) ion in real samples under optimized conditions. The results for the analysis of tap water samples are summarized in Table. 1 . Three replicates were analyzed by using the same electrode. 
The results obtained by the proposed method were in satisfactory agreement with those obtained by the ICP analysis as presented in Table 1. These findings clearly demonstrate that the constructed sensor could be applied for precise and accurate determination of trace-level of Zn (II) ion in real samples. A comparison between the proposed sensor and our previously reported ones [42] clearly shows that the high efficiency of the prepared sensor are related to the synergic effects of functionalized MWCNT and nanoparticle sized IIPs that produced in controlled ratio of cross linker/monomer equal to 8.

\section{Conclusion}

A novel electrochemical sensor was developed for determination of Zn (II) ion by SWASV technique, through modification of GCE by IIP/MWCNT nanocomposite material. The nanocomposite material was successfully characterized by FT-IR, TGA, and SEM. The oxygen functionalized MWCNT was used to enhance the surface area, electron transfer kinetics, and enhance Zinc (II) diffusion during an electrochemical process. Under optimal conditions, the IIP/MWCNT exhibited an excellent electrochemical performance toward Zn (II) ions together with a wide linear range, high sensitivity, a low limit of detection $\left(5 \times 10^{-12} \mathrm{~mol} / \mathrm{L}^{-1}\right)$, and good repeatability. The fabricated sensor was also applicable in monitoring the Zinc (II) in real samples from tap water.

\section{Declarations}

\section{Acknowledgements}

The support of this work by research grants from the NSTRI and Azad University Research Council is gratefully acknowledged.

\section{References}

1. M. Murakami, T. Hirano, Cancer Sci. 99, 1515 (2008)

2. G. Zengin, Environ. Earth Sci. 70, 3031 (2013)

3. S.M. Shaheen, F.I. Eissa, K.M. Ghanem, H.M. Gamal El-Din, F.S. Al Anany, J. Environ. Manage. 128, 514 (2013)

4. K. Bellir, M.B. Lehocine, A.H. Meniai, Desalin Water Treat 51, 5035 (2013)

5. D. Mohan, K.P. Singh, Water Res. 36, 2304 (2002)

6. J. Juan, Pinto, Anal. Methods. 4, 147 (2012)

7. X. Ding, M. Nomura, T. Suzuki, Y. Sugiyama, T. Kaneshiki, Y. Fujii, J. Chromatogr. A 1113, 182 (2006)

8. C.M.G. Van Den Berg, P.J.M. Buckley, Z.Q. Huang, Estuar. Coast. Shelf Sci. 22, 479 (1986)

9. H. Duwensee, M. Adamovski, G.-U. Flechsig, Int. J. Electrochem. Sci. 2, 498 (2007)

10. K. Tyszczuk-Rotko, K. Pietrzak, A. Sasal, Adsorption 25, 913 (2019)

11. N. Promphet, P. Rattanarat, R. Rangkupan, O. Chailapakul, N. Rodthongkum, Sens. Actuators, B 207, 526 (2015) 
12. A.H. Alghamdi, J. Saudi Chem. Soc. 14, 1 (2010)

13. R.W. Jakubaa, J.W. Moffett, M.A. Saito, Anal. Chim. Acta 614, 143 (2008)

14. C.M.A. Brett, M.B.Q. Garcia, J.F.C. Lima, Anal. Chim. Acta 339, 167 (1997)

15. W. Geremedhin, M. Amare, S. Admassie, Electrochim. Acta 87, 749 (2013)

16. H. Wang, Y. Liu, G. Hu, Y. Ye, L. Pan, P. Zhu, S. Yao, J. Electroanal. Chem. 857, 113736 (2020)

17. S. Rodsud, W. Limbut, J. Electrochem. Soc. 166, B771 (2019)

18. L. Wang, Y. Wang, Q. Zhuang, J. Electroanal. Chem. 851, 113446 (2019)

19. A. Abellan-Llobregat, C. Gonzalez-Gaitan, L. Vidal, A. Canals, E. Morallon, Biosens. Bioelectron. 109, 123 (2018)

20. A. Noorbakhsh, A. Salimi, E. Sharifi, Electroanalysis 20, 1788 (2008)

21. A. Salimi, A. Noorbakhsh, M. Ghadermarz, Anal. Biochem. 344, 16 (2005)

22. A. Salimi, A. Noorbakhsh, M. Ghadermarzi, Sens. Actuators B Chem. 123, 530 (2007)

23. A. Salimi, B. Pourbahram, S. Mansouri-Majd, R. Hallaj, Electrochim. Acta 156, 207 (2015)

24. S. Fortunati, A. Rozzi, F. Curti, M. Giannetto, R. Corradini, M. Careri, Biosens. Bioelectron. 129, 7 (2019)

25. A.A. E-H. Ahmed, M.A. Korany, M.M. Khalil, Microchem. J. 157, 104909 (2020)

26. Z. Xiao, J. Elike, A. Reynolds, R. Moten, X. Zhao, Microelectron. Eng. 164, 123 (2016)

27. B.-T. Zhang, X. Zheng, H.-F. Li, J.-M. Lin, Anal. Chim. Acta 784, 1 (2013)

28. M.R. Ganjali, N. Motakef-Kazami, F. Faridbod, S. Khoee, P. Norouzi, J. Hazard. Mater. 173, 415 (2010)

29. Y. Zeng, D. Yu, Y. Yu, T. Zhou, G. Shi, J. Hazard. Mater. 217, 315 (2012)

30. Z. Zhang, Y. Hu, H. Zhang, S. Yao, J. Colloid Interface Sci. 344, 158 (2010)

31. M. Roushani, T. Musa Beygi, Z. Saedi, Spectrochim. Acta A Mol. Biomol. Spectrosc. 153, 637 (2016)

32. W. Ma, X. Du, M. Liu, F. Gao, X. Ma, Y. Li, G. Guan, X. Hao, Chem. Eng. J. 412, 128576 (2021)

33. A. Kumara, A. Baloucha, A. Ashfaque, A. Pathan, Polym. Test. 77, 105871 (2019)

34. Y.-H. Zhu, Z.-L. Zhang, D.-W. Pang, J. Electroanal. Chem. 581, 303 (2005)

35. C. Branger, W. Meouche, A. Margaillan, React. Funct. Polym. 73, 859 (2013)

36. M. Khajeh, Z.S. Heidari, E. Sanchooli, Chem. Eng. J. 166, 1158 (2011)

37. T. Alizadeh, S. Amjadi, J. Hazard. Mater. 190, 451 (2011)

38. M. Shamsipur, H. R. Rajabi, S. M. Pourmortazavi, M. Roushani, Spectrochim. Acta, Part A. 117, 24 (2014)

39. M. Kim, Y. Jiang, D. Kim, React. Funct. Polym. 73, 821 (2013)

40. L. Thi, M. Hoa, Diamond Relat. Mater. 89, 43 (2018)

41. J. Gayathri, K.S. Selvan, S. Sangilimuthu, S.S. Narayanan, Sens. Bio-Sens. Res. 19, 1 (2018)

42. N. Behnia, M. Asgari, A. Feizbakhsh, J. Environ. Chem. Eng. 3, 271 (2015)

\section{Figures}




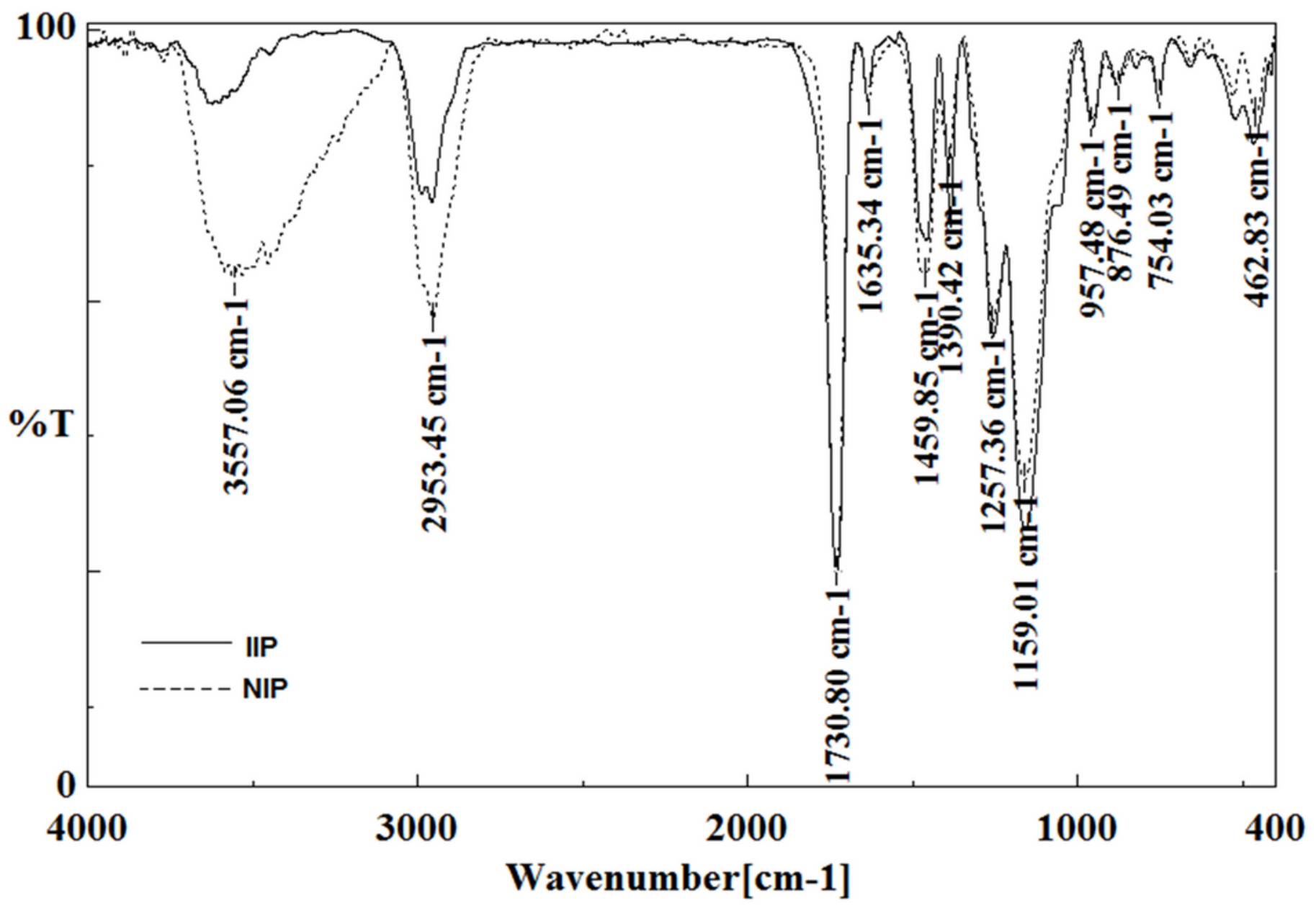

Figure 1

The FT-IR spectra of un-leached (NIP) and leached zinc imprinted polymers (IIP) 


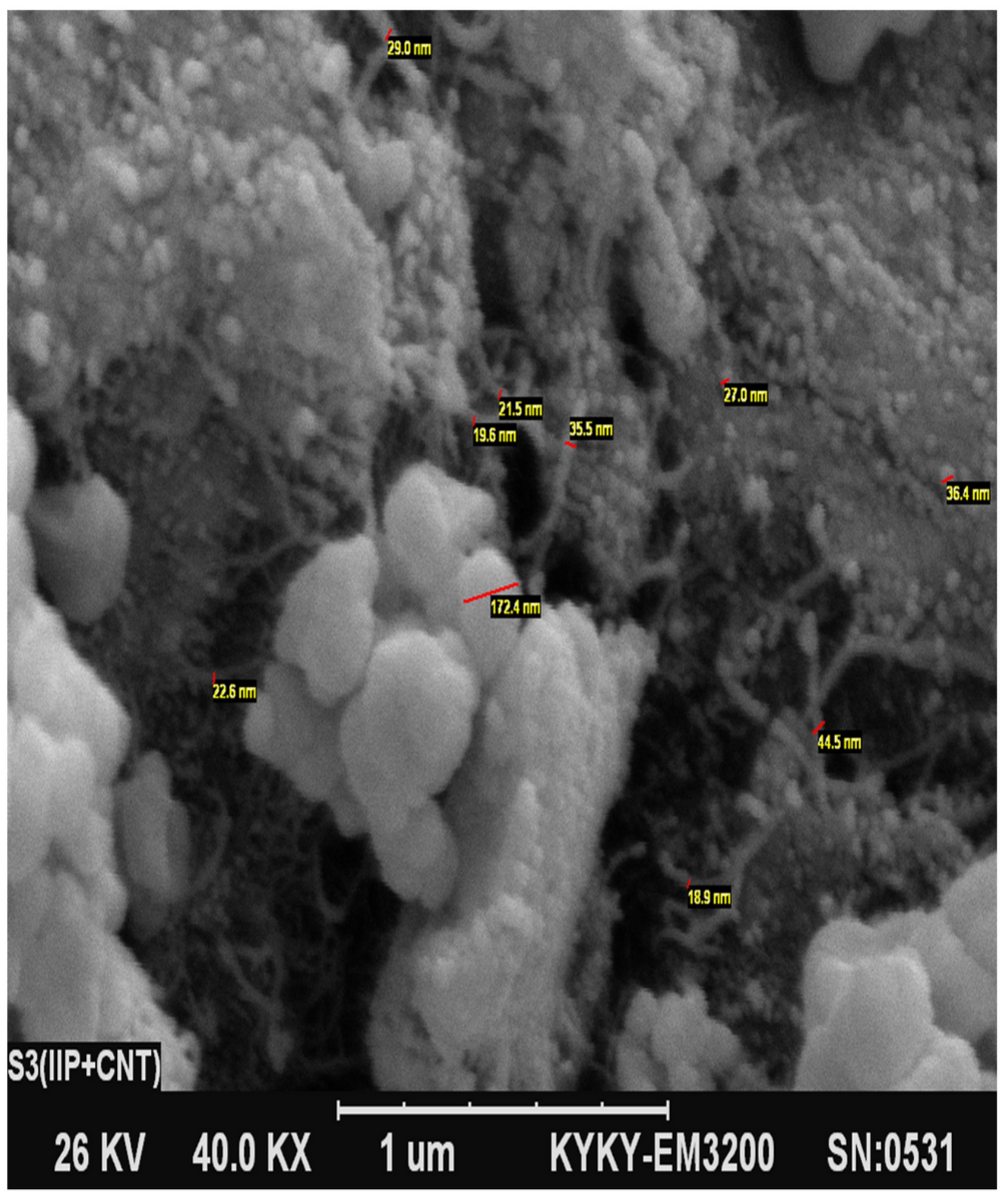

Figure 2

The SEM image of the three-dimensionally microporous structure of IIP-MWCNT films on the GCE surface 


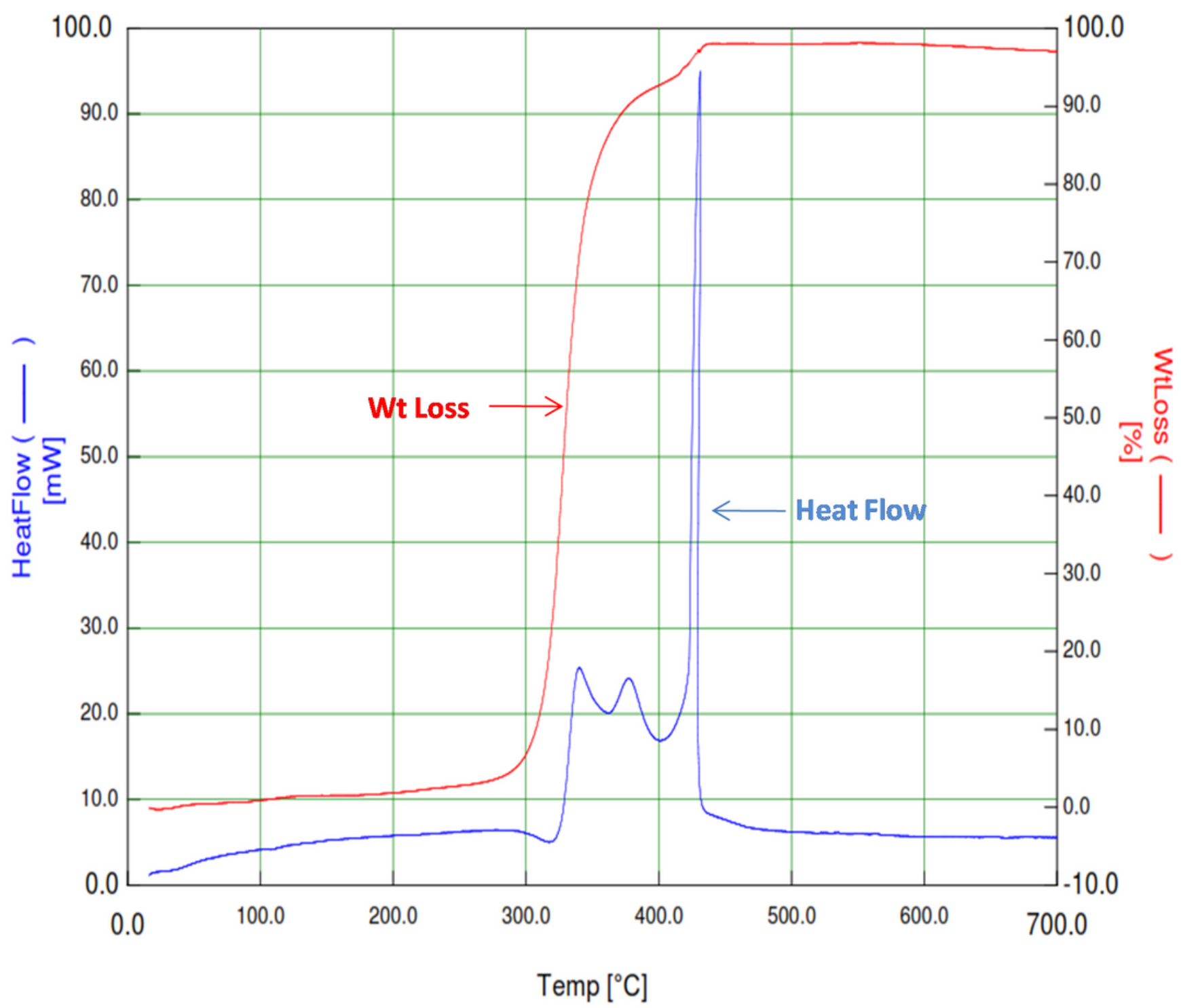

Figure 3

TGA curve of synthesized IIP 

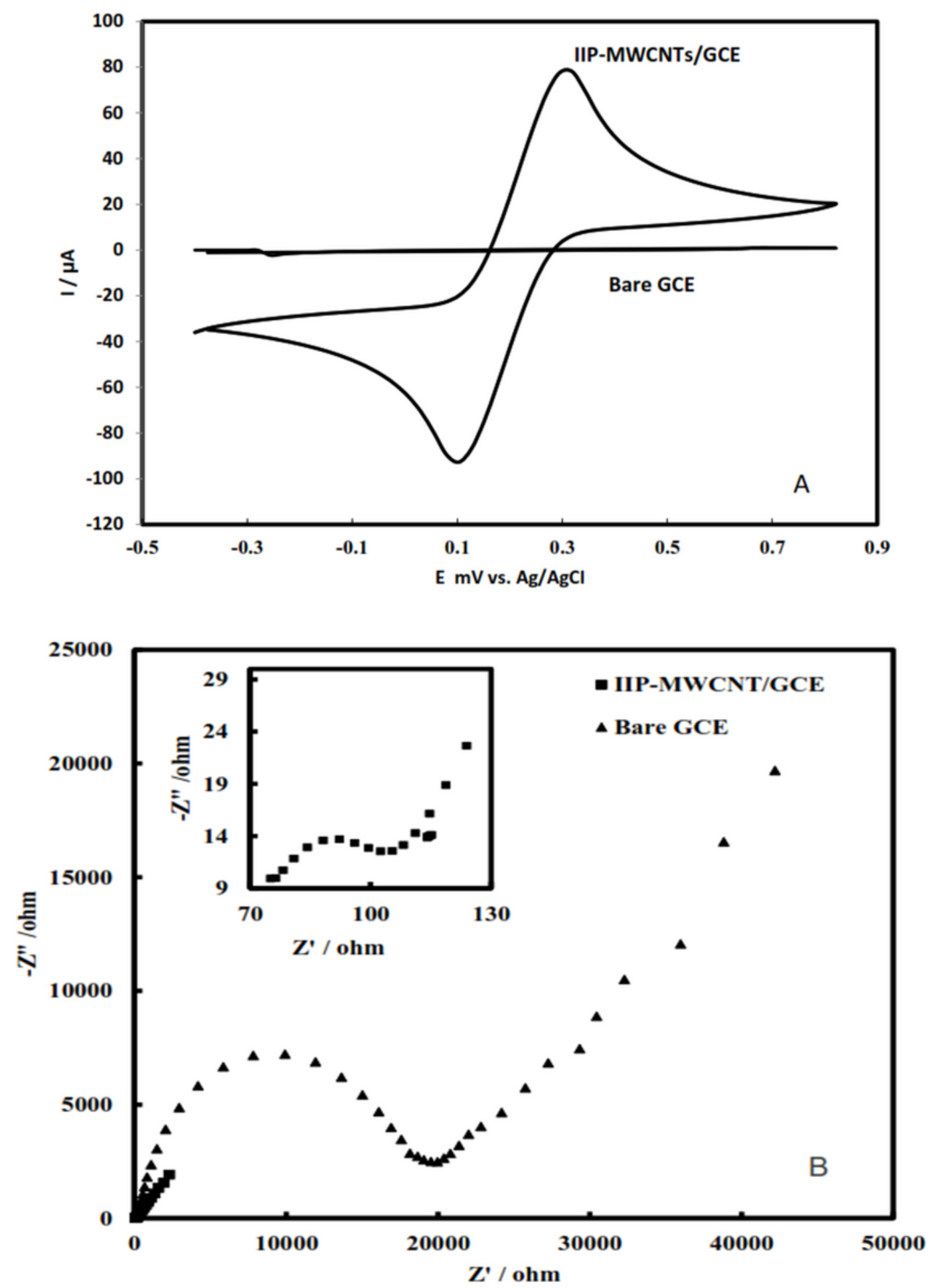

Figure 4

(A) Cyclic voltammograms of bare GCE and IIP-MWCNT/GCE modified electrode in presence of $5 \mathrm{mM}$ $\mathrm{K} 4 \mathrm{Fe}(\mathrm{CN}) 6,0.1 \mathrm{M}$ phosphate buffer solution (pH7.0) at a scan rate of $50 \mathrm{mVs}-1$. (B) Nyquist plots for bare GCE $(\boldsymbol{\Delta})$ and IIP-MWCNT/GCE ( $\square$ ) in $5 \mathrm{mM} \mathrm{Fe}(\mathrm{CN}) 63-/ \mathrm{Fe}(\mathrm{CN}) 64-, 0.1 \mathrm{M}$ PBS solution (pH7.0), and at potential $250 \mathrm{mV}$. The frequency was swept from 100 to $0.01 \mathrm{kHz}$; modulation potential $10 \mathrm{mV}$ 


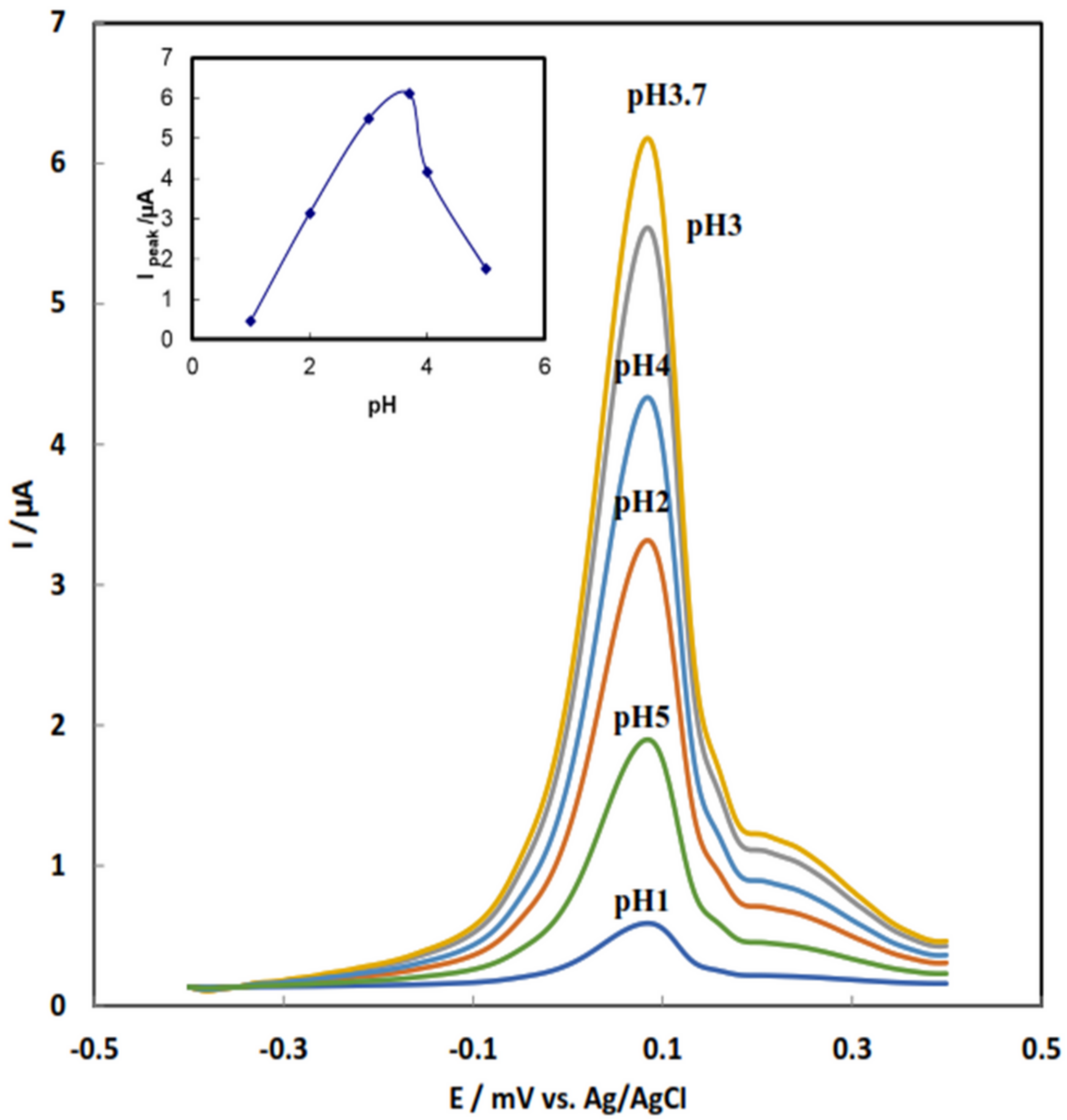

Figure 5

Effect of $\mathrm{pH}$ upon the stripping voltammetric response of 1.0×10-6 $\mathrm{M} \mathrm{Zn} \mathrm{(II).} \mathrm{The} \mathrm{square} \mathrm{wave}$ voltammograms were recorded at scan rate of $50 \mathrm{mVs}-1$; pulse amplitude, $50 \mathrm{mV}$ 

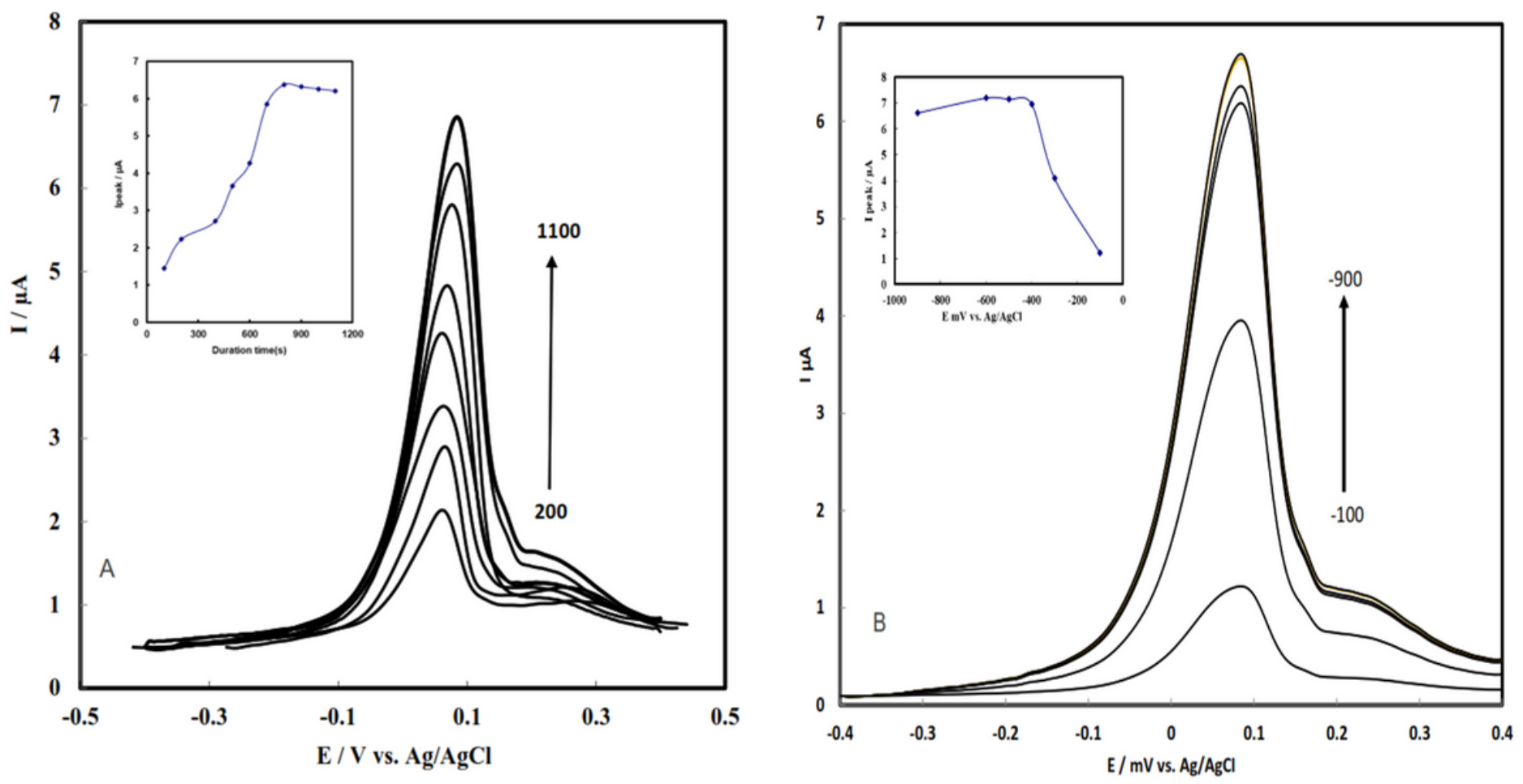

Figure 6

(A) Effect of accumulation time upon the response to 1.0×10-6 M Zn (II) after accumulation potential of $-500 \mathrm{mV}$ and $\mathrm{pH} 3.7$ at scan rate of $0.05 \mathrm{Vs}-1$ and pulse amplitude of $0.05 \mathrm{~V}$. (B) Effect of accumulation potential upon the response to $1.0 \times 10-6 \mathrm{M}$ Zn (II) after accumulation for $800 \mathrm{~s}$ 


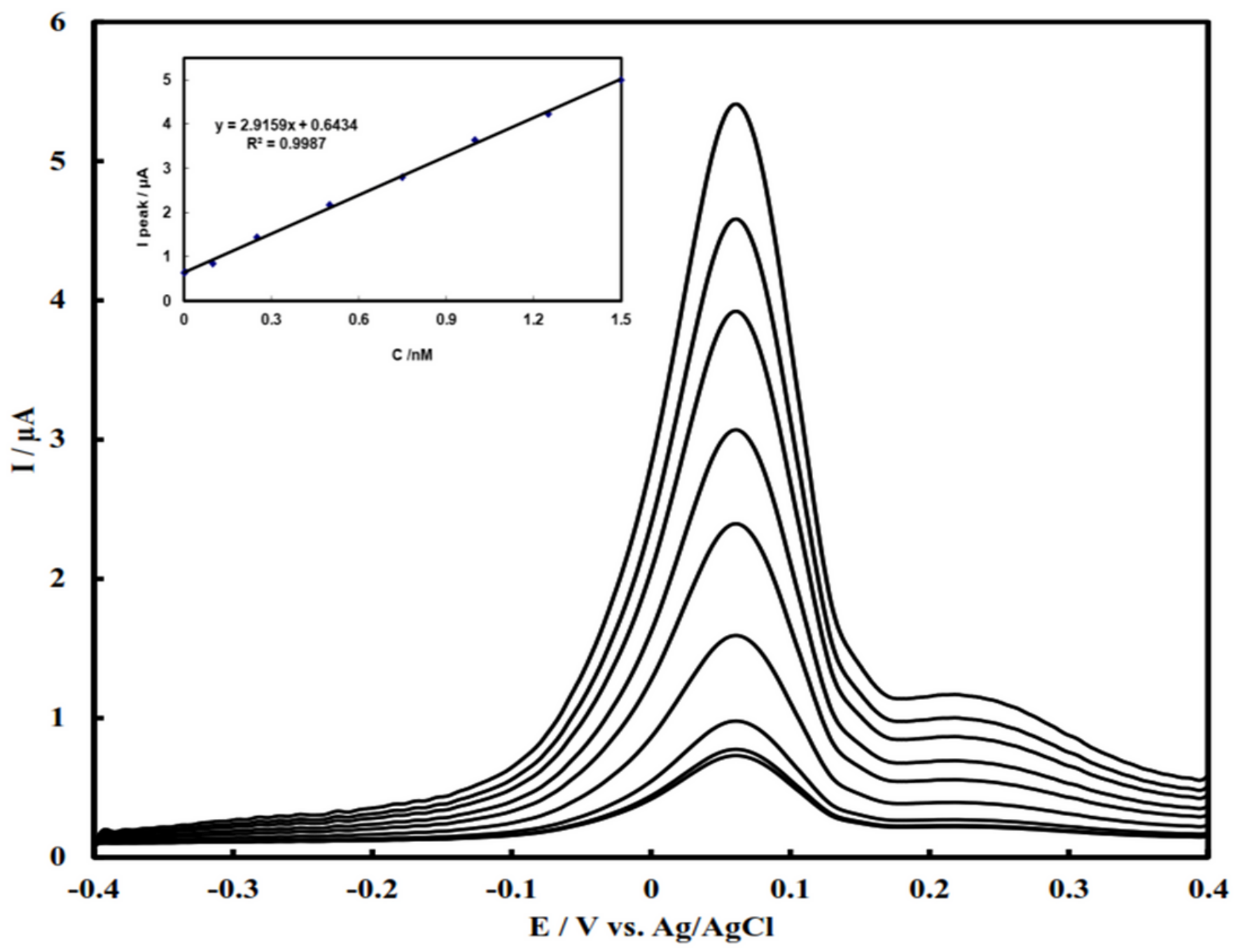

Figure 7

Square wave Stripping voltammograms for concentration of $\mathrm{Zn}$ (II) from 0.001-1.5 nM. The square wave voltammograms were recorded at scan rate of $0.05 \mathrm{~V} \mathrm{~s}-1$ and pulse amplitude of $0.05 \mathrm{~V}$. Accumulation time and the accumulation potential were $800 \mathrm{~s}$ and $-400 \mathrm{mV}$, respectively. (Inset) Calibration curve of $\mathrm{Zn}$ (II)

\section{Supplementary Files}

This is a list of supplementary files associated with this preprint. Click to download.

- Table.1.tif 